\title{
Research on Flipped Classroom
}

\section{Acupuncture \& Moxibustion Bilingual Teaching}

\author{
Xiang-Wen Meng \\ College of Acupuncture and Massage \\ Tianjin University of Traditional Chinese Medicine \\ Tianjin, China \\ mengxiangwen@139.com \\ Dong-Hong Meng \\ Tianjin Academy of Traditional Chinese Medicine \\ Affiliated Hospital \\ 13034346102@163.com
}

Jia-Jia Ma

College of Acupuncture and Massage

Tianjin University of Traditional Chinese Medicine

Tianjin, China

1072478767@qq.com

\author{
Wen-Tao LV \\ College of Acupuncture and Massage \\ Tianjin University of Traditional Chinese Medicine \\ Tianjin, China \\ 714354365@qq.com \\ Ya-Chao Zheng \\ College of Acupuncture and Massage \\ Tianjin University of Traditional Chinese Medicine \\ Tianjin, China \\ 1582468176@qq.com \\ Yu-Xuan Zhang \\ College of Acupuncture and Massage \\ Tianjin University of Traditional Chinese Medicine \\ Tianjin, China \\ 1527173062@qq.com
}

\begin{abstract}
Acupuncture and moxibustion" is a clinical course. The demand worldwide of alternative treatments makes the bilingual teaching in courses as acupuncture and moxibustion to become imperative. It's a priority to find out a way for the students to improve clinical language skills of acupuncture in a short time with international standards. The idea is to use Methods like the preliminary thinking of bilingual teaching of Traditional Chinese Medicine. This paper studies the shortcomings in the current bilingual teaching of acupuncture and moxibustion, and puts forward the practice of flipped classroom so as to make further improvement of bilingual teaching in acupuncture and moxibustion in higher education institutions and universities. The Results obtained using the flipped classroom of the bilingual teaching of acupuncture and moxibustion in our university show that the ability of the students in the clinical practice using English language has been highly improved. As a Conclusion, the bilingual teaching can improve continuously. This method can not only stimulate the students' autonomy in bilingual learning but also improve their skills of medical English. Furthermore, following this method we assure a good bilingual education for our students in traditional Chinese medicine.
\end{abstract}

Keywords—acupuncture; bilingual teaching; flipped classroom

\section{INTRODUCTION}

The study of subjects as acupuncture, moxibustion and based traditional Chinese medicine worldwide demand the creation of a bilingual teaching method that has become one of the most commonly used teaching methods in the TCM institutions. Although many students graduate every year

2016 Educational reform project of Tianjin University of Traditional Chinese Medicine obtaining the highest marks, there are still quite a few problems in the teaching process. The quality of the education of Chinese medicine, especially for those who can't only master it but also to spread the knowledge of TCM to the world becomes essential. As a result, a lot of institutions specialized in the study of TCM are already using the bilingual teaching method. However the question is how to establish the best quality in the study of the traditional Chinese medicine for master students using a foreign language in the clinical practice and in their academic research.

Through the preliminary thinking on the bilingual teaching of TCM, this paper studies the shortcomings of the current bilingual teaching of acupuncture and moxibustion and proposed flipped classroom which aims to make further improvement of bilingual teaching in acupuncture and moxibustion in TCM college and universities and spreads the traditional Chinese medicine overseas[1][2][3].

\section{PROBLEMS OF ACUPUNCTURE BILINGUAL TEACHING METHOD}

\section{A. Absenting rationality of teaching problem}

In the learning progress, students from TCM University find a lack of continuity in acupuncture and bilingual courses, without reinforcing each other. For example, acupuncture course is offered to undergraduate students but bilingual course is offered to master and doctor students. The time difference burden the students with extra effort which means they have to relearn acupuncture while studying bilingual lessons. 


\section{B. Absenting flexibility of course arrangement}

Because of the different English levels among the students, their performance in class varies wildly. On one hand, the high English level students understand faster so as to have more interests to learn acupuncture which enhance their clinical learning as well.

On the other hand, for the low English level students, it is harder to study and remember the contents of the course affecting their motivation, thus forming a vicious circle that may influence their clinical practice.

\section{The lack of speaking}

Although in bilingual teaching method, the professor will ask the students to do oral practice such as dialogues, due to limited time and closed class, the specific vocabulary for acupuncture in English is rarely used.

\section{Single assessment mode}

At present, the assessment mode of bilingual teaching method is still a simple written examination which makes the students learn just for marks not to get the knowledge. The application of bilingual teaching method can't improve the student's ability, thus makes bilingual teaching in name only.[4][5]

\section{THREE STAGES OF FLIPPED CLASSROOM}

In order to carry out bilingual teaching programs of acupuncture and moxibustion effectively and systematically, we have proceed according to the previous research, and used in teaching practice the "Clinical Manual of Acupuncture and moxibustion" (Editor Xiangwen Meng). This book divides flipped classroom with English in three stages.

\section{A. Stage I the name and type of the disease}

Students of traditional Chinese medicine have the basis of ordinary English, but they lack professional knowledge of medical English. With the medical English, Chinese students can have international communication and master an indispensable tool in modern medicine. Paying attention to the basic theory of TCM, the formulas of Chinese medicine and treatment based on syndrome differentiation theory of TCM; the role of bilingual teaching should be highlighting the "syndromes" and common clinical symptoms of "disease". So to become a candidate of the international exchange program, one must master the common clinical symptoms of diseases in English language.

This stage includes the study of basic and specific English language for the subject. In response to this situation, flipped classroom placed the emphasis in the teaching of the English name of those diseases that can be better treated by acupuncture. In addition, learning the susceptible disease in foreign nomenclature is also important, Such as Irritable Bowel Syndrome (IBS), Chronic Fatigue Syndrome, and Multiple Sclerosis (MS) and so on. In flipped classroom, the goal is to study different kinds of disease and consolidate through specific English medical cases of illness. Flipped classroom strengthens the students' ability of self-learning and understanding. In spare time, they review their lessons through writing exercises and asking questions to each other.

\section{B. Stage II. Clinical dialogue}

The student book used in class is basically the "Clinical Manual of Acupuncture and moxibustion" (Editor XiangWenMeng). Other medical books in English can be used as a complement for the lessons. Students train their language skills by oral dialogue exercises and listening skills by exercises in the classroom or in their spare time. At the same time, this method encourages foreign students and local students to participate in the classroom discussions and English clinical dialogue training. In the practice, it's important to bring four TCM diagnose methods in to play and inquiry comprehensive and purposeful. Learning to explain the theory of TCM included basic concept of traditional Chinese medicine and acupuncture and moxibustion principles. In clinical diagnosing process, students should be able to use simple and understandable language to explain the situation clearly which requires a systematic practice.

The conversation trainings should incorporate following points. Give full attention to the characteristic of TCM four diagnosis method, i.e. observation (looking), auscultation (listening), Interrogation (asking) and palpation (feeling the pulse). Among these, interrogation is one of the vital techniques which involve mainly listening to patient and asking questions. On the basis of the "Asked Ten Songs", a case of the full-scale interrogation involves listening to complaints of patient and asking purposeful questions according to the chief complaints of the patients.

Paying attention to cultural difference and communication taboos of east and west is most important. In clinical receptions, mastering in Chinese considerations and at the same time paying attention to the English communication habits and etiquette is very crucial. While communicating, euphemisms sentence patterns and very polite way should be used like "Could I help you..." Or "Could you tell me..." etc. Since western countries' people are more concerned to their privacy, religion, age, weight and other problems, so when meeting such a sensitive topic; more attention should be paid to language appropriately and avoid causing unnecessary misunderstanding.

Students should be able to explain basic concepts of traditional Chinese medicine and acupuncture treatment principle. As vigorously carried out international exchanges and clinical scientific research achievements, the curative effect of traditional Chinese medicine is gradually accepted by more and more countries and regions. Unique theoretical system of TCM for people is becoming more and more interesting; so in the process of diagnosis, questions could be inevitably asked to the doctors. For example: what are the channels and collaterals? How acupuncture can relieve the pain? How doctors of traditional Chinese medicine "cure" the disease? What's the meaning of "tongue observation"? And so on. In the process of explaining, students will use a brief and simple language to explain. So students are required to study systematically, summarize the ideas and practice properly. 


\section{Stage III. Acupuncture and Moxibustion writing in English}

Reading and Writing English Literature Related to Acupuncture and Moxibustion. After the two stages before, the name and type of the disease, and clinical dialog, students have made a great improvement in vocabulary, listening and speaking skills. Based on this, with the flipped classroom teaching method, the students are required to access some information, write English version summary or articles such as a brief introduction to a disease, an explanation of the basics of acupuncture which aims to improve their English writing ability in acupuncture and moxibustion. And holding meeting on the topic of acupuncture.

Another important part is to be able to think and design clinical and scientific research tasks. So after they become familiar with the writing of professional papers in English, students are required to retrieve The American Journal of Chinese Medicine, The Journal of Clinical Acupuncture and Moxibustion or SCI journals in English. This will put them on forefront of clinical and scientific researches in TCM and they will be able to think and design a foundation for clinical research projects in the future.

Educational practice has proved that flipped classroom has greatly enhanced students' enthusiasm in acupuncture \& Moxibustion in English and received remarkable effect.

\section{ADVANTAGE TEACHING METHODS OF FLIPPED CLASSROOM}

\section{A. Change passive learning into autonomous learning}

First, students are required to define their task in the acupunctural bilingual learning in order to help them to cultivate a good study habits and autonomous learning ability. For instance, while learning the name and type of the disease, students can only make their best on the basic of understanding.

In clinical diagnosing process, students need to analyze the disease by what they have learned and give clinical inquiry and solution according to the teaching material.[6][7]

\section{B. Learning by group}

After stage I and II, students are divided into groups and ask to do a role play, one student perform as a doctor, the other as a patient. It aims maximizing the time to let students practice language and clinical dialogue in class. For role playing, students need to gather a lot of material, discuss related issues, do scene practice before class and make supplement after class. It not only helps teachers to master their teaching results quickly, analyze the difficult parts deeply but also encourages communication and develops team spirit among the students.

\section{Arranging class reasonably and expanding the content of}

Flipped classroom provides the students with opportunities for language training and comprehensive analysis. Lots of clinical dialogue and inquiry practice, student-centered and explanation of TCM diseases with English which free students from nanny teaching and passive learning, help them to understand clinical English communication clearly. Teachers make comments, suggestions or supplements for the group role playing and encourage the other students give their views, ant improvise. This arouses the class; maximize time and expanding content of class teaching.

\section{SUMMARY}

Bilingual teaching method is a hot topic in the current education reform in China, an inevitable trend with education reform and international standards. Bilingual teaching in TCM universities has made great progress and cultivates many bilingual talents. Bilingual flipped classroom is able to promote the teaching contents, methods and teaching measure reform.

This teaching mode can stimulate the students to get the initiative learning in bilingual learning and improve their medical English level, thus meeting the demand of their study. To get better results in the teaching program, it's necessary to improve the structure and to delve deeper, so that to attain our goals in implementing bilingual teaching wildly and cultivate more high-quality TCM bilingual talents.

After three years of practice, five hundred and three grades of students have been trained by this teaching method. On one hand, most of the students' basic language and clinical communication skills have been improved, especially explaining TCM theory in English. On the other hand, some outstanding students help as an interpreter at the hospital or in international academic conference. Last year, 10 students over 20 from one TCM class took the responsibility of translation in an international academic conference or at the hospital, building and improving their English ability. And a student was admitted to Melbourne University, Australia to start the M.A. program.

Teaching practice indicates that flipped classroom greatly enhances students' enthusiasm of learning acupuncture in English, receiving remarkable teaching results.

Next, we will make improvement on the evaluation system of flipped classroom and delve deeper in optimal integration of acupuncture bilingual teaching.

\section{ACKNOWLEDGMENT}

Project source: 2016 Educational reform project of Tianjin University of Traditional Chinese Medicine

\section{REFERENCES}

[1] Xu YunXiang. The exploring of bilingual teaching of acupuncture and thinking [J]. Chinese acupuncture 2006, 26 (9): 673-675.

[2] Zhao Ling, Shen XueYong, Zhang HaiMeng. The research of "bilingual teaching" about Meridians [J]. Journal of Shanghai university of traditional Chinese medicine, 2007, 21 (2): 12-14.

[3] Wang Wei. Acupuncture bilingual teaching experience [J]. China's higher medical education, 2004, (3): 16-17

[4] Zhang Jieying, Meng Xiangwen. Experience and thinking of bilingual teaching in the university of Traditional Chinese medicine [J]. Henan Traditional Chinese medicine, 2013, 33(6): 871-872.

[5] Li Lin, Meng Xiangwen. "Acupuncture and moxibustion" bilingual "three-step modular" teaching method practice and research [J]. Henan Traditional Chinese Medicine, 2013,09:1552-1553.

[6] MAO Jiaoyan. On the Advantages and Application Challenges of Flipped Classroom Mode [J].Time Education,2014,07:197-198. 
[7] MIAO Jingmin,WANG Qiong. Preliminary Findings on the Flipped Classroom pedagogy:A Survey in Chinese Higher Education [J].Open
Education Research,2015,05:74-82. 